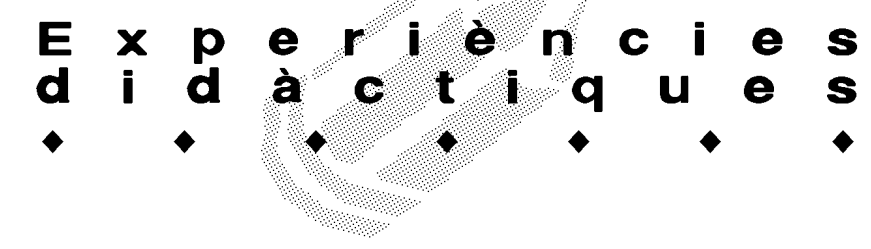

\title{
MORTADEL·LO I FILEMÓ, UNA GRAN OCASIÓ. REFLEXIONS I RECURSOS SOBRE COM INTRODUIR EL CÒMIC A L'AULA D'UNA FORMA AGRADABLE
}

\author{
Enric Ramiro Roca. Departament d'Educació. Universitat Jaume I de Castelló
}

Ningú no pot discutir a les acaballes del segle $X X \mathrm{i}$ portes del $X X I$, que vivim en un món dominat per la imatge. La imatge s'imposa en les vendes, les compres, la vestimenta, les relacions públiques, la indústria, els serveis i gran part de les activitats humanes. En la societat actual poques persones poden fugir del seu domini i influència, acceptats més o menys conscientment. Tanmateix, són minoria els qui es preocupen davant aquesta realitat, i la majoria opta per seguir una dinàmica que li és favorable sense reflexionar sobre el metallenguatge utilitzat. De fet, la nostra actitud és molt diferent si es tracta d'un missatge escrit, on normalment reconeixem $\mathrm{i}$ interpretem sense dificultat els senyals emprats, i un missatge visual davant el qual adoptem una postura de simple consum al faltar-nos els mitjans descodificadors.

És la imatge on la persona adopta una postura més passiva i, per tant, la informació que hi comporta és acceptada voluntàriament per l'individu, de forma que s'incorpora ràpidament i significativa, sense cap procés defensiu o analític per la seua part. D'ací la necessitat urgent d'una educació audiovisual a tots els nivells, sense la qual no podrem tindre una idea ajustada de la realitat que estem vivint.

El còmic, a més d'un instrument lúdic que no cal oblidar, és un mitjà de comunicació amb entitat pròpia, que agafa elements d'altres mitjans d'expressió. Del cinema utilitza els plànols, el seu encadenament i els angles de mira; de l'art gràfic, la composició d'imatges, la perspectiva, el color, l'ombra i la llum; de la literatura, els textos, els diàlegs $i$ els signes convencionals, i del teatre, les expressions facials, els gests corporals i el conjunt de l'actuació. Per tant, quan treballem el còmic estarem també treballant aquests mitjans i a la inversa, endinsant-nos en un mar de relacions i riquesa molt més complex del que puga semblar a simple vista.

\section{Qui no haja llegit «tebeos», que alce la mà!}

Les historietes són realment una eina quotidiana per introduir la descodificació visual d'una forma senzilla, agradable i fàcilment acceptada per l'alumne, principi fonamental perquè siga significatiu el seu aprenentatge, amb tot el que comporta de durador en el temps i constructor de conceptes.

Vista la importància de conèixer el llenguatge visual, podríem adoptar un doble sistema d'aprenentatge basat al mateix temps en l'observació i manipulació d'imatges, de forma que s'aconsegueix entendre els codis i possibilitar el seu ús de forma conscient. Així, la introducció del còmic a l'aula i en general de l'estudi de la imatge (per favor, una altra assignatura més, ni pensar-ho!) és una tasca que s'ha de realitzar de forma immediata en el sistema educatiu si no volem «garbellar aigua» com diu el nostre refranyer popular. I això no vol dir abandonar el clàssic aprenentatge oral i escrit de la llengua, però sí ser reflexius sobre el marc actual en què ens trobem. De fet, generalment la paraula reprodueix en la ment una 0 diverses imatges úniques, de forma distinta en cada individu en atenció a múltiples factors, com les vivències o l'estat físic i anímic en què es trobe. Imatges i paraules estan íntimament lligades i relacionades de manera singular en cada persona, i per tant, si ensenyem la lectoescriptura als nostres alumnes, també hem d'estar extremament atents amb la cultura visual. Perquè, quantes hores es passen els alumnes llegint quan vénen a classe, i quantes hores davant d'informació visual? I quan no vénen a classe? I quan no són alumnes?

\section{Aleshores, què podem fer?}

Per començar, tindre en compte tota aquesta problemàtica i reflexionar ja és un pas endavant. El següent pas podria ser la lectura d'alguns dels manuals que us suggerim tot seguit al voltant del tema, i també l'assistència a cursos i xerrades si us fa falta, o millor encara la creació de seminaris i grups preocupats pel món de la imatge, a fi de poder fruir pel camí de la felicitat crítica. De l'acceptació i posada en pràctica de tots aquests camins estem segurs que són les circumstàncies les qui manen: salut física i mental, companyies, ambient familiar, relacions laborals amb l'alumnat i companys, 


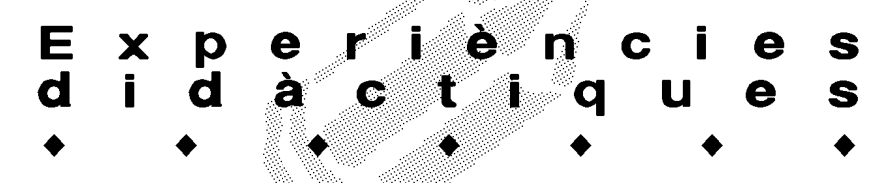

edat, vivències i frustracions... Però a la fi l'últim responsable ets tu: digues sí i comença a fruir llegint historietes i utilitzant-les a classe, i ja veureu com a poc a poc les trobareu supernecessàries i us convertireu en còmicodependents.

Afortunadament en la societat actual, i al pas que anem cada vegada més, ens trobem amb nombrosos materials sobre qualsevol tema, i no es tracta tant de falta d'informació com de criteris per a la tria, a fi de no marejar massa i anar directament al tema. Amb aquesta idea i una sèrie de limitacions que ens hem imposat: practicitat, editorials conegudes, ultraselecció i economia de compra, us recomanem tres títols:

[ACEVEDO, JUAN. Para hacer historietas. Editorial Popular, 2a edició. Madrid. 1964. 208 pàgines]. És un llibre ben aprofitat, amb una descripció i tipologia de tots els elements del còmic usats d'una forma molt senzilla i amb una alternativa viable per a aprendre a utilitzar el llenguatge de la historieta. A més, té com a objectiu formar el poble en la seua més ètica realitat, en la mateixa línia de l'alfabetització de Paulo Freire.

[ALIBÉS, M. DOLORS i JAN. Com es fa un còmic. Col-lecció «L'espiell», editorial Onda. Barcelona. 1990. 40 pàgines]. Llibre a tot color, representa els ossos bonics de la metodologia de la historieta. Amb un llenguatge clar, divulgatiu i agradable sintetitza de forma gràfica i amb poques paraules la riquesa que li podem traure al còmic per treballar-lo a classe. Són pàgines per a poder-les utilitzar directament amb l'alumnat.

[OSCAR DÍAZ, M. FERNÁNDEZ. El cómic en el aula. Col-lecció «Innovaciones pedagógicas», editorial
Alhambra. Madrid. 1990. 181 pàgines]. Pràcticament està dividit en tres blocs: llenguatge i recursos del còmic, elaboració d'un còmic a l'aula, formes d'utilització didàctica i altres idees. Recull de forma didàctica multitud de suggeriments i aporta una gran quantitat d'activitats al final de cada text, així com nombroses imatges i esquemes.

Com a material de lectura i treball, disposem de nombroses editorials i títols amb els quals podem anar construint la nostra comicoteca, de forma que únicament us comentaré breument una simple panoràmica d'aquelles que tenen els materials en la nostra llengua i que normalment són les més desconegudes a nivell general. Per començar per algun Iloc, tenim els llibres de Charlie Brown i Snoopy a Edicions 62 i els de Tonnuci a Barcanova, ambdós com una mostra inesgotable d'idees per fruir lúdicament i didàctica. L'editorial Joventut també té en la nostra llengua a tot color els clàssics Tintín, i els posteriors Quico i Flupi; Jou, Zette i Jocko; Yakari; Cori; Yoco Tsuno; i les últimes col-leccions de January Jones; El professor Palmera; Harry Dickinson o el Senyor Barelli, ens ofereix un panorama ric, divers i sovint desconegut.

Tampoc Edicions B es queda darrere, amb la reedició dels Arxius del TBO (hi ha un magnífic monogràfic que arreplega tots els invents) i l'actualitzada Família Rovelló; i els encisadors Barrufets i múltiples sèries com Mortadel-lo i Filemó; Zipi i Zape; Super Llopis; la Jungla Boja; Cedric; Jojó; Timoteu; Jimmy Totsol; Estarrufat; Grans Paròdies; Frank Margerin; Jack Pelman o Noies de Blanc. L'increïble Astèrix, a Dargaud-Grijalbo, i Per-
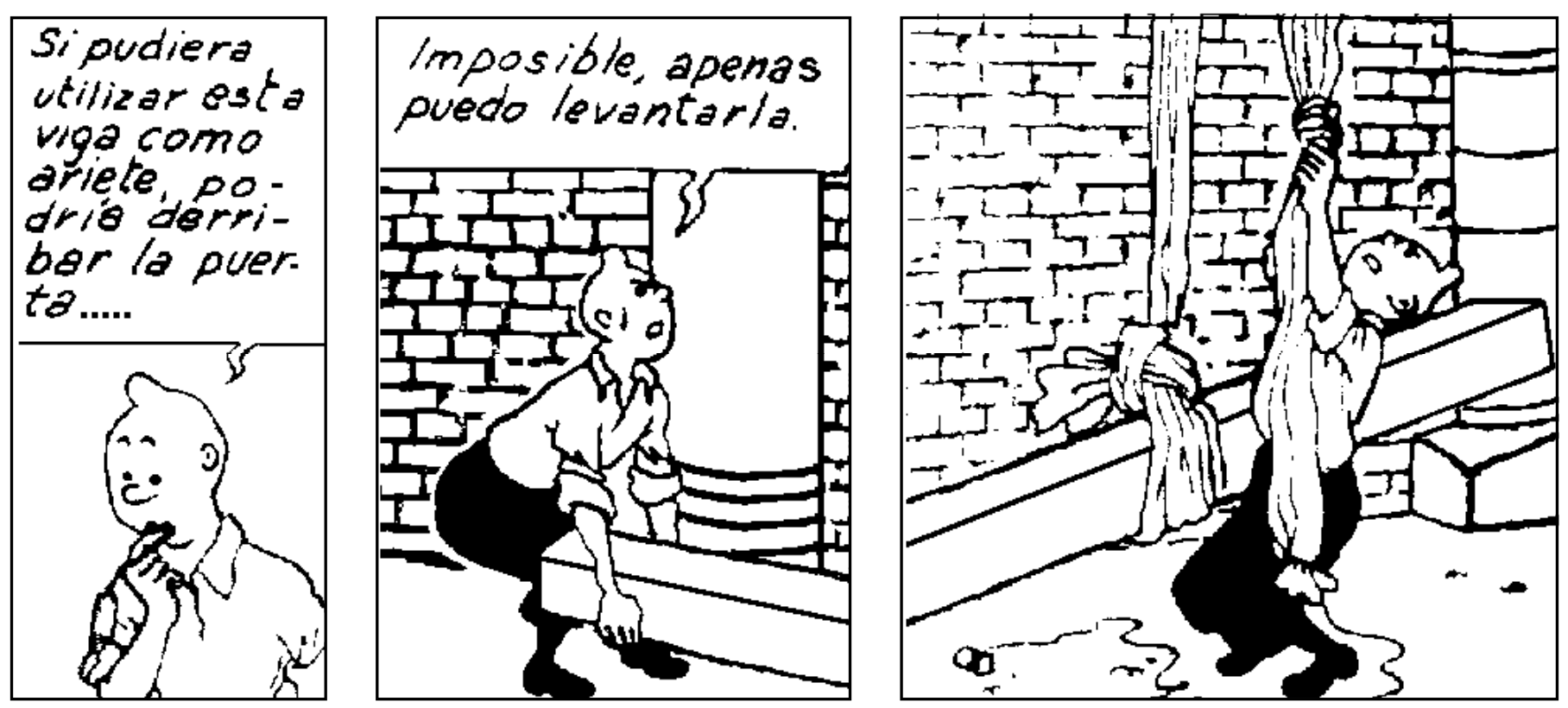


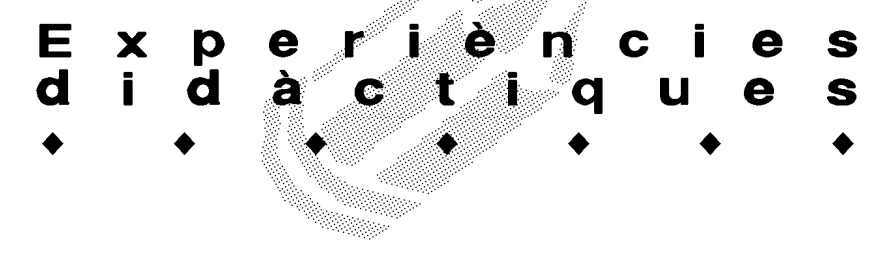

cevan a Junior-Grijalbo són altres títols que cal afegir. Capítol a part mereix la coalició «Petita galeria. Enigmes i aventures», quatre deliciosos volums amb una barreja de passatemps, historietes, literatura, imaginació i observació. I al nostre àmbit lingüístic podem fruir de la simpàtica revista Camacuc al País Valencià i Cavall Fort a Catalunya, unes publicacions dedicades per complet al còmic $\mathrm{i}$ que també ens ofereixen un munt de possibilitats a la nostra mà... que cal només aprofitar. I si tenim ordinador, no us pergau els CDs interactius d'OT el Bruixot.

Evidentment hi ha molta més bibliografia, però la nostra experiència ens aconsella que la millor forma d'iniciar-se en un tema és amb pocs llibres i molt clars, i són aquests els que us recomanem, sense que això vulga dir que són els únics o els millors. I si per casualitat no els trobeu o no és un tema que us interesse excessivament, passe a assenyalar-vos algunes possibilitats que teniu per a treballar-lo a la classe des de demà mateix.

\section{Però què podem fer a classe, ja?}

Mentre aneu a comprar els llibres i aneu llegint-los, us propose quinze activitats diverses en continguts, nivells $i$ àrees per anar fent boca amb aquells materials d'historieta que tingau més a prop:

- Ordenar vinyetes prèviament desordenades.

- Indicar la utilitat de certs aparells que apareixen i inventar-ne d'altres.

- Imaginar què hi ha darrere d'una porta, dins d'un poal...
- Dramatitzar les historietes.

- Recollir signes convencionals que apareixen a les vinyetes i inventar-ne.

- Canviar els títols de les historietes, els diàlegs...

- Jugar a endevinar els títols.

- Classificar les vinyetes d'una historieta i comentarles: vinyetes violentes, normes de conducta...

- Proposar canvis de final o d'inici de les historietes, justificant-los.

- Classificar els personatges d'una historieta en raó del sexe i les funcions que fan.

- Calcular la superfície de cert tipus de vinyetes: on apareixen dones, animals, violència...

- Analitzar les vinyetes: plànols, format, globus, línies cinètiques, onomatopeies, angle de visió, text, expressions.

- Fer còmics sobre temes determinats: ecologia, educació vial, coeducació, educació per a la salut...

- Utilitzar vinyetes per a alegrar les llibretes i les monografies.

- ...(a disposició del lector de la comunicació).

Com hem pretès demostrar, el còmic és un univers d'esplai i saber que es troba en un moment molt ric $\mathrm{i}$ variat en la seua oferta, i també en la nostra llengua. Esperem que el seu ús s'incremente a l'escola i fora d'ella a nivell didàctic, com a recurs, com a eina interdisciplinària (periodisme, teatre, imatge...) i especialment de forma lúdica perquè contribuisca a eixa anhelada felicitat crítica i compartida que desitgem a totes i tots.

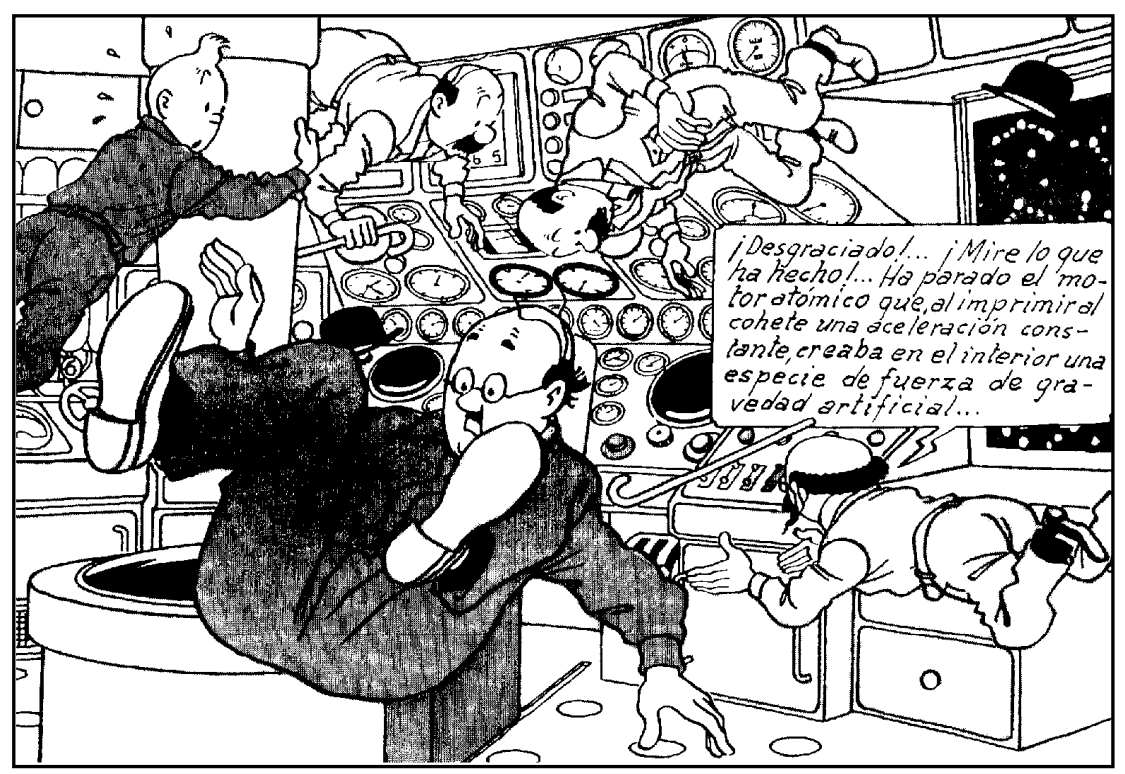

